\title{
An Innovative Method for Reducing Phonological Errors in EFL Learners
}

\author{
Razieh KashefiKhishan \\ International Center for Teaching Persian to Non-Persian Speakers \\ Alzahra University (AAZFA)
}

\begin{abstract}
Many teachers struggle with this issue and make many pronunciation errors when distinguishing English syllables and Persian syllables. Considering the theory of generative phonology, two groups of language learners with a total of 30 participants were analyzed to obtain more accurate results. A general education approach was used for the first group, and an education approach focusing on listening and speaking was used for the second group. The participants in the first group watched movies in original language twice over the course of 18 sessions, and the training in the second group focused more on speaking and listening every two sessions. Also, simple sentences were selected from the Top Notch Fundamentals books A / B for both groups to read, and their voices were recorded. A significant difference in pronunciation was observed in the second group when the recorded sounds of both groups were compared. Following that, the researcher compared the data with ten language learners who were members of the first group of language learners and were learning the language at an advanced level. In spite of the fact that the level of the second group was lower than that of the 10 learners, they made fewer mistakes. Based on the research findings, it appears that students' phonological errors are significantly reduced when using education based on short films in the original language and focusing on speaking comprehension.
\end{abstract}

\section{Introduction}

One of the controversial issues in phonology is phonological errors. This phenomenon is a process in which in some languages, the linear arrangement of sounds is disrupted under certain conditions. In all languages, phonological errors are mostly found as speaking errors and a common phonological feature among children [1]. Listening skill plays a very important role in learning a second language, and for this reason, it has been used as a basis for special methods, such as the natural approach [2]. The reason for this importance is that $40-50$ percent of communication time is devoted to listening, 25 - 30 percent to speaking, 11 - 16 percent to reading, and 9 percent to writing [3]. The purpose of the present study is to determine that phonological errors are less in which of the two groups that were trained in two different methods and durations. The distinction between English syllables and Persian syllables is a category that is very basic in language learning because it is the origin of the major pronunciation errors of language learners. Therefore, this area requires the efforts of teachers and more accurate training of distinctions in the form of short conversations and emphasis on listening skills (including the use of the movies in original language with purposeful methods). It seems that the phonological errors of the learners will be reduced by using the educational method based on short films in original language and more emphasis on the listening comprehension of the learners.

According to some linguists, such as Trotsky and Jacobson, the goals of phonology and phonetics should be different. They attempted to provide a comprehensive classification of phonetic properties and believed that the phonetics of sounds examines language by considering their physical and physiological properties, i.e., sound articulations in the physical system (acoustics) and in productive articulations, articulators of language speakers are examined, while in phonology, the role of sounds within the structure and phonetic system of a particular language is examined [4]. Phonology is related to morphology and is not directly related to physics and physiology (material aspects).

Considering that the main purpose of this research is analysis of English pronunciation of Persian speakers, the researcher attempted to select simple sentences from Top Notch Fundamentals A/B books, and asked learners to firstlyintroduce themselves in English and then record their voice.

Analytic research method was used, and data were collected using field study. Research statistical population included 60 Persian speakers who were trained English in general and specialized groups. Collected samples included recorded speeches of language learners about the simple sentences selected from Top Notch Fundamentals A/B books.

\section{Literature Review}

Hwang and Yim [5] explored the professional Identities of native English-speaking teachers 
(NESTs) and non-native English-speaking teachers (NNESTs) at South Korea primary schools, relying on Bourdieu's concept of hegemonic relation. Findings of the study showed that two different types of symbolic capital, e.g., native- speakerism and qualified tenured teacher positions shape the dynamic of hegemonic relations constructed an antagonistic collective habitus between NESTs and NNESTs. Results of the study indicated theoretical importance of ideology of native-speakerism for strengthening the students' desire to acquire native English and avoid localized variants of English. Negative attitudes toward CALD of localized variants of English were due to the threatening nature for the sustainability of the students.

Fang [6] in a paper challenged the ideology of standard language and native- speakerism and discussed how these ideologies may influence the recruitment of teachers and intercultural communication in English language teaching (ELT). Accordingly, they used narrative inquiry of Chinese EFL professional with education experience abroad to show the way of negotiating professional identities in relation to privilege and marginalization, working with native English-speaking coworkers. The article challenges the ideology of native-speakerism in various aspects of ELT to argue the significance of going beyond the idealized native speaker model from $\mathrm{GE}$ paradigm.

Bayyurt [7] conceptualized EFL as the byproduct of interaction between individuals from various linguistic and cultural backgrounds in multilingual and multicultural contexts, who only share English as the common language. She argued for the EFLawareness including awareness about intercultural language and instructional practice and language learning, as a significant and essential component of teacher training courses. Accordingly, she investigated the intercultural EFL- awareness of nonnative English language teachers (NNESTs) teachers in terms of their perception of culture in their teaching practice in Turkey. Relying on aspects of Adaskou et al. [8] definition of culture and its subcategories, findings of the study indicated the overlap of the subcategories indicating the fluid and dynamic nature of culture as a concept shaped and re-shaped in different cultural contexts. Moreover, it was found that in terms of the NNESTs' perception of involvement of culture in their teaching practice, they considered development of intercultural awareness through class activities as significant. However, this view was not in line with their teaching materials. The NNESTs also supported the presentation of non-standard forms of English in their classroom, as an awareness-rising context among their students on realistic use of English.

Roberts, Burkinal, and Footo [9] conducted a study entitled 'Reduction of phonological processes' was conducted based on speeches of 154 children from age of 2.5 to age of 8 . Some of the results of this study include the decrease in the use of processes between the ages of 2.5 and 4 years, which a significant reduction is observed at the age of 2.5 in the duplication, onset consonant deletion, vowel mutation, and derivation processes. However, the clusterreduction, gliding, and deaffrication processes are among the common processes at the age of 4 .

Kingston [10] in his article entitled "Phonological features from the perspective of Moscow and St. Petersburg phonological schools" studied the phonetic system features of the language and stated that in the specific phonology of a particular language, sounds of that language are investigated in terms of the way of meaning generation, its mental and abstract aspects, the way and the possibility of learning sounds together, and matters related to the clarity and ambiguity of sounds from the semantic and auditory comprehension perspectives. He points out that phonological approaches are not the same in different schools. In the Moscow phonological school, phonetics is quite different fromphonology, and adds that the potential and basic state of any phoneme is in the root of words and in its morphologicalstates, a subject that in phonology only its actual possibility is examined.

Bernthal and Bankson [11] conducted a study based on the speech of 1,000 children aged 3 to 9 years, which revealed a number of processes, including gliding, cluster simplification, final consonant deletion, and stopping processes are used for a longer time in different age groups, and as the syntax of syllables and consonant clusters becomes more complex, the frequency of occurrence of these processes increases.

\section{Theoretical Framework}

The present research is based on theory of active speech articulators proposed by [1] and [12]. In this theory, which is proposed in the new generative and generative phonological schools, language phonemes are analyzed and according to the active speech articulators. The theory of active speech articulators was proposed in the framework of generative phonology. To this end, between the phonological and phonetic levels of the language, there is an intermediate level known as the allophonic level through which the phonemes of the language are written to the sounds of speech, or they appear phonetically. In addition, each phoneme is a family of similar sounds that are distributed complementarily to each other. These similar sounds are represented by language allophones. The allophonic level in generative phonology is also specially considered. However, generative phonology, the allophonic level is implicit in the phonological level; in other words, this phonology does not consideran independent level called the allophonic level. 
Words are stored in the minds of speakers as a chain of phoneme elements, each composed of a set of phonological features. According to [13], [12], [14] and [1], phonological features fall into two categories: one category include features independent of active speech articulator that specify phonemic units in terms of being voiced or voiceless. The (+ voiced) units include vowels, glides, nasal consonants, and liquid consonants that do not essentially cause significant obstruction in the articulatory system. Among these phonological classes, vowels and glides have the ([- consonant]) feature and nasal and liquid consonantshave the ([+ consonant $]$ ) feature. Voiceless units ([- voiced]) consist of obstruent consonants that are divided into threeclasses: stops, affricates, and fricatives. These consonants are distinguished from each other using the [continuous] attribute. Thus, stop consonants have the [-continuant] feature, fricative consonants have the [+continuant] feature, and affricate consonants have the [-continuant, + continuant] feature. Also, the [lateral] feature distinguishes the lateralconsonant /1/ ([+lateral]) from other ([- lateral]) consonants. The other category is the active speech articulatordependent features that characterize the speech articulators creating obstruction in the articulatory system. In general,the speech articulators are active in the three main cavities (oral cavity, nasal cavity, and pharyngeal cavity) in the articulatory system.

James [15] conducted a study based on speeches of 50 Australian children entitled 'Application of phonological processes in Australian children aged 2 to 7 years' and divided them into 7 age groups. Considering the table presented by James entitled "Approximate age of elimination of phonological processes", it is found that the most common processes applied by children are vocalization, cluster reduction, gliding, and vowel shifts, and with increasing age, number and frequency of occurrence of these processes decrease and the consonant cluster, consonant sequence and number of syllables are effective in the occurrence of vocalization process in all age groups, the percentage of occurrence of two processes of gliding and cluster reduction up is higher in average up to 5 years of age.

\section{Phonological Errors}

Since long time ago and with the evolution of linguistic knowledge, especially in contrastive analysis, important linguistic factors, such as identifying types of errors, causes of errors, how to correct errors, and preparing and formulating texts compatible with errors have been considered by language teachers and researchers. Therefore, in order to achieve a better educational situation and also to facilitate the teaching and learning of a second language, research studies have been conducted since the beginning of linguistic knowledge up to now [16].
Hosseini [17] identified two main factors as the origin of phonological errors. To this end, errors originating from the second language are called Intralingua or Developmental errors, and errors originating from the first language are called Interlingua or interference errors. In classification proposed by Keshavarz [18] four processes, including incorrect phoneme placement, phoneme increase, phoneme reduction, and incorrect phoneme sequence have been mentioned in the occurrence of phonological errors [19].

\section{Foreign/ Second Language Learning}

Psychologists have reached two important hypotheses about language learning and have proposed various hypotheses regarding the ways of learning and teaching human languages. In addition, scientists' research on language descriptions and language behavior contributes to our knowledge of the stages preceding in language learning and the factors that hinder the language learning process. Meanwhile, the teacher should obtain useful information from linguistics, psychology, and other related sciences in order to guide in the selection, grading, and presentation of language elements for learning and developing the skills learned. For understanding and analyzing the texts, the learner should strengthen his or her intelligence so that he or she can memorize all of the units of sound, and when he or she hears them, can place them together to make sense of them and give the signs to another language. Speaking skill is far more complex because the learner must:

1. Decide what he wants to say.

2. Choose the pattern for speaking.

3. Choose the words that are appropriate and have the ability to convey his/her meaning.

4. Use the correct order of the sounds and the sound pitch and tone.

5. Use his/her tongue and lips in a specific position for articulating sounds and do all this spontaneously andunconsciously [20].

Learning a second language involves achieving the following points:

1. A series of personal habits, such as pronouncing sounds in a certain way or adding certain suffixes to wordsbased on the already learned rules.

2. A series of linguistic and cultural subjects.

3. Ability to comprehend and construct correct Speech sentences in social and cultural situations in appropriateplaces.

Active participation of learners in the learning process is a basic premise for two common learning 
hypotheses. The cognitive cade theory emphasizes the principle that the learner has an innate mental ability to learn. He/she uses his/her perception in relationships as well as the subconscious regulation of laws resulting from findings in structuring and organizing new material and his/her understanding in relation to previously known material. The more the student has relation to what has been learned, the more he/she can make progress in learning.

The learning process will be much easier if the material is moved in a bottom-up way and from the known to the unknown and from the simple to the complex issues. The development of habits also requires constant repetition. The learning of each skill is directly related to the amount of practice, and the repetition of the presented courses should be done with certain intervals.

\section{Learning and Listening Strategies}

According to Chamot [21] learning strategies include specific texts, perspectives, or activities that are applied to thelearner for facilitating learning and retrieval of linguistic and content information. Listening comprehension strategies can include processing, correlation, and classification, all of which must be considered [22]. He emphasizes the active role of language learners in the use of strategies and states that the term Strategy includes trying or facing problems that if the person faces them correctly will succeed in his/her work.

Learning strategies include comprehension, internalization, and regulation of usable findings for learner, while communicative strategies emphasize successful transfer and reception of message. Learning and communicative strategies are sometimes in relation and sometimes match with each other, since, in a sense, communicative strategiesare the same as communication techniques necessary for learning [22]. The difference between learning techniques and learning strategies can also be demonstrated by observable practical processes, such as note-taking and invisible mental processes. In general, for better learning, all intra-mental and extramental activities shouldbe regulated, controlled, and evaluated, and the teacher should consider both aspects.

Language skill is another important principle for the competent listener. No listener can comprehend the material wellunless he/she has reached a certain level of language proficiency, which not only involves mastering the features of the phonetic and grammatical system, but also requires mastery at the discourse level [23].

Different activities should be conducted at the same time in language learning courses and teaching one skill separately from the other skills will not be very useful and practical. As a result, combining the listening with speaking and possibly note-taking, reading and writing is a suitable combination for learning and expanding the capability of language learners at different levels of learning [24].

\section{Standard English}

The notion of 'native speaker' leads us to another important argument that has to do with 'standard English'. In this respect, one discussion that we will undoubtedly encounter is that standard English is 'correct English' and that is therefore essential to teach standard English to those who are willing to learn it, Another current discussion of English language standards has to do with "national categories" based on which many teaching methodologies are designed since if this notion "ceased to be the basis for thinking in applied linguistics", many methodologies would lose their concept of 'native speaker' [25]. This variety of English which is in fact no better and no worse than any other variety but widely — though erroneously - believed to be the English language. This implies that other varieties are 'deviations' from the 'norm' and represent 'corruptions' due to certain reasons [26]. That is exactly why in almost all accessible ELT materials, Standard English models are basically the main available ones and those who subscribe to this view feel that the best way to solve the conflicts raised by these 'violations' is simply to get rid of all nonstandard accents in English.

However, the concept of "Standard" for English similar to many other languages is a controversial issue. There are doubts whether one can easily define such a complicated issue. In his single-page treatment of the topic, Trughill tries to fully describe this important variety of English which is "widely known as standard English" by attributing it to an "educated" way of speaking, the way English is used in writing, radio and television or the form this language is "taught to foreign learners". Yet he finally asserts that any attempt to "define standard English" is an impossibility since standard English similar to other varieties of English is not a "fixed" entity with "welldefined labels" and therefore it lacks "clear-cut wellestablished boundaries" due to some "marginal features" that often occur.

In spite of this, there are still a number of scholars such as Claus Gnutzmann who emphasize the use of Standard English as the only linguistic model for ELT [27] without considering that the very idea of standard implies 'stability' and the fact is language is by nature 'unstable'. Widdowson is basically against the notion of standard and believes that there is just no sense in sticking to one standard form which is only spoken by a few people. Pushing this issue a bit further, Trudgill adds that there are firstly a vast majority of people who speak standard English with "regional accents" and secondly if the standard accent is not regional such as 'R.P. accent', 'B.B.C. English' and the 'Queen English' in Britain, you can find 
internal differences to state that these accents do not sound exactly the same [26]. Biases of this kind towards nonstandard varieties of English do not therefore have any linguistic or scientific roots.

Standard English and accent are often characterized as 'good English' and according to Trudgill there is prejudice against nonstandard varieties due to "social" and "cultural" reasons or values. As a result, some accents in English are socially stigmatized. In this regard, Holliday [25] makes an attempt to critically clarify on the issue of standard. He professes that what is generally referred to as standard is often a "brand" of English rather than a "national language" such as British English, which has appealed many speakers as a model because it is "prestigious". This tells us that the standard should be prestigious so that it "satisfies the need for high status models". It should also be "cultured" in the sense of "being rooted in something Other and external" or above and beyond imagination. Finally, the standard should be "non-centred" in the sense that it should not be invented by the "Centre" to improve the "Periphery", and should not therefore imply any form of "us-them relationship- which is the source of inequalities.

What's more, in many linguists' opinions like Trudgill, it is very hard to define what Standard English is [28]. Following them, we have had an increase in the number of experts who are strongly critical towards teaming paradigms "favoring native speaker language norms in ELT". Barbara Seidlhofer and Jennifer Jenkins are two of those who legitimize nonnative speaker accents [29]. The fact is as Crystal, Jenkins and Kachru believe emphasis on the use of a so-called nonstandard variety of English with international intelligibility is more common among scholars than learners [30]. There are also scholars like Rajagopalan [31] who go to extremes when they argue that with the advance of English as an international language the whole idea of 'native speaker' has been "rendered somewhat bluffed, if not hopelessly meaningless" The findings of a survey conducted among future English teachers in Germany [12] also reveal that students are "fairly open to teaching materials that include a variety of native speaker and normative speaker accents". They have all been receptive to the main pronunciation objective which is international intelligibility not nearnativeness.

\section{Studying the role of errors in the language learning process}

We have all more or less experienced that language teachers consider errors of language learners to be detrimental to learning and insist teaching in such a way that the learner never makes errors. Their justification is that what is learned by error remains an ingrained habit in the individual, and it is difficult, and eliminating or replacing other habits with unpleasant ones is difficult and sometimes impossible. At first glance, this justification seems logical, but it should be noted that how children learn their mother tongue. Do not they make errors? Is the children's language perfect from the beginning? On the other hand, it might be said that learning is a kind of trial and error, and therefore it can be concluded that the learner's linguistic error is not only an interfering factor, but also an indication of testing the pervasive hypothesis that ultimately leads to proper learning [24].

In second language learning, a new language system, separate from his/her mother tongue system, is formed in the learner's mind. This system is not complete at first, it is rather in an intermediatelevel between the first and second language systems, and for this reason it is called the intermediatesystem. Due to the continuity of learning processes, this system is gradually expanding and gets closer and closer to the language system of second language speakers [24].

\section{Data Analysis}

In order to prove the research hypothesis, two different groups of language learners were analyzed. The first group was composed of 30 ones in general course who were taught English in a general approach. The second group was composed of 30 ones in a private course who were taught English in a specialized approach through higher emphasis on speaking and learning.

In the first group, twice original language films were represented during 18 sessions. In each session, a part of the film was displayed in the class. Then, the sentences used in the film were reviewed and repeated in the class with learners. In the second group, film approach was used onceevery two sessions as follows:

After watching the film, the learner was asked to speak in English about what he/she had watched. Learners generally retold everything they remembered about the film in English sentences. (In the meantime, all the pronunciation errors of the learner were mentioned by the teacher). The learner then answered a number of questions about the film. After checking the answers, the film was displayed again for the learner and he/she this time was asked to repeat sentence by sentence. At the end, the film was displayed to the learner once again. The learner was again asked to speak inEnglish about what he/she had watched and to answer the questions about the film (the learner showed a considerable change in terms of pronunciation when retelling the film, compared to thefirst time and a larger number of questions were answered correctly).

The only source used for the first group was Top Notch and only the material of this book was used in the class and the teacher proceeded according to the contents of the book and the learner'sreading, writing, 
listening and speaking skills were learned based on this book's content. However,in addition to this book, the second group had to work on Tactics for Listening as homework as follows:

1. In the first time, the learner listens to the text without looking at it.

2. In the second time, the learner looks at the text and repeats loudly sentence by sentence (repetition continues as long as the learner is sure he/she correctly hear the sentence), highlights new words and sentences and writes down their meaning.

3. In the last time, just listen without looking at the text.

The above points made the learners pay more attention to what they were listening to. For the first time, carefully listening to the text without looking at it, gave them an overview of what was in the text.The second time, by looking at the text and repeating it aloud sentence by sentence until they weresure that they hear properly and can repeat the sentence correctly, the learners noticed their listening and speaking errors and attempt to eliminate them. Moreover, by highlighting new sentences and words and writing down their meanings, they could expand their mental lexicon. The last time, by listening to the text without looking at it, learners realized that they can better recognize the words and sentences within the text and understands better what is in the text.

The second group was also asked to write an essay once every two sessions on one of the everydaytopics (e.g., shopping, traveling, climate) and talk about it in class. All English-Persian equivalents were practiced with examples in the second group. When writing essays on each topic and talkingin class, the teacher pointed out their pronunciation errors and practiced with them their correct forms and provided other examples for them to better understand. Researcher selected simple sentence from Top Notch Fundamentals $\mathrm{A} / \mathrm{B}$ books and asked both groups to read aloud these sentences so that their voice was recorded. When the recorded voices of both groups were analyzed, a significant difference was found in pronunciation of the second group. In the next step, the researcher compared these data with 10 language learners who were learning the language at an advanced level and were in the first group. Although the level of the second group was lower than that of these 10 participants, they made fewer errors. The first groupwas learning the language at an advanced level, but 10 of the second group were at a lower level. After reviewing the data, it was found that the second group, who were learning the language at alower level than the first group, but were learning in the classroom with special training, had fewerpronunciation errors than the first group, who were studying at the advanced level.
Table 1 analyses the errors of language learners participating in the general course. The language learners participating in the specialized course did not make these errors. However, it should be noted that not only general language learners but also the largest number of specializedlanguage learners had difficulty in distinguishing and using the two phonemes of / ð / and / $\Theta$ / correctly. Language learners of specialized approach mostly used / $\Theta$ / instead of / ð /.

\section{Conclusion}

In this paper, phonological errors of Persianspeaking English learners were analyzed from the re generative phonology perspective. According to the research results, by using the educational approach based on short films in the original language and putting more emphasis on learners' listening comprehension, their phonological errors were reduced. Besides, listening to the text and repeating its sentences can have a positive effect on the correct pronunciation of language learners. By repeating sentence by sentence according to what they have heard, they can be more confident and make less pronunciation errors. This was evident in the second group. Findings demonstrate that by using the educational approach based on short films in the original language, phonological errors of learners can be reduced. In this study, after watching the film, the learners spoke in English and retold everything they remembered about the film in the form of English sentences. Meanwhile, all the pronunciation errors of the learner were identified and corrected.The learner then answered a number of questions about the film. In the end, a considerable change was observed in the learner in terms of pronunciation when retelling the film, and the number of questions he/she had answered correctly was increased. The approach applied to the second group for language learning made learners place more emphasis on their listening skills. Various exercises in classroom and at home made them have fewer phonological errors in speaking. Therefore, the success of the second group in speaking skill, especially in the pronunciation of English words and less phonological errors, indicates that the research hypothesis is supported.

\section{References}

[1] Spencer, A. (1996). Phonology. Oxford: Blackwell.

[2] Krashen, S., and Terrell, T. (1983). The Natural Approach: Language Acquisition in the Classroom. Hayward, California: Alemany Press.

[3] Rivers, W. M. (1981). Teaching Foreign Language Skills. (2nd ed.), Chicago, IL: University of Chicago Press.

[4] Samareh, Y. (2015). Persian Phonetics. University Publication Center. 
[5] Hwang, K. and Yim, S., Y. (2019). The Negative Influence of Native-Speakerism on the Sustainability of Linguistic and Cultural Diversities of Localized Variants of English: A Study of Local and Expatriate Teachers in South Korea. Sustainability, 11.

[6] Fang, F., G. (2018). Native-speakerism revisited: Global Englishes, ELT and intercultural communication. Indonesian Journal of English Language Teaching, 13(2), 115-129.

[7] Bayyurt, Y. (2017). Non-native English language teachers' perceptions of culture in English language classrooms in a post-EFL era. In J. Dios Martinez Agudo (Ed.), Native and Non-Native Teachers in English Language Classrooms (pp. 139-160). Germany: Library of Congress.

[8] Adaskou, K., Britten, D., and Fahsi, B. (1990). Design decisions on the cultural content of a secondary English course for Mororcco. ELT Journal, 44(1), 3-10. DOI: 10.1093/elt/44.1.3.

[9] Roberts, J. E., Burchinal, M., Footo, M. M. (1990). Phonological process declines from $21 / 2$ to 8 years. Journal of communication Disorders 24, 204-217.

[10] Kingston, J., and Cohen, A. H. (2013). Extending Articulatory Phonology. Phonetics 49: 194-204.

[11] Berntal, F. E., and Bankson, N. (2014). Articulation and Phonology disorders. Boston: Ally and Bacon.

[12] Kenstowicz, M. (1994). Phonology in generative grammar. Cambridge, Mass. and Oxford: Blackwell. Pp. ix +704 .

[13] Halle, M. (1992). Phonological Features. New York. Oxford University Press. Hayward, K. 2000. Experimental Phonetics. England, Longman.

[14] Stevens, K. N. (2000). From Acoustic Cues to Segments Features and Words. 5 th ICSLP, Vol1, 1-8.

[15] James, D. G. H. (2001). The use of phonological processes in Australian children aged 2 to $7 / 11$ years. Advance in speech- Language Pathology 3: 109-127.

[16] Ladefoged, P. (2006). A course in phonetics. $5^{\text {th }}$ ed. U.S.A - Boston. MA: Thomson press.

[17] Hosseini, Z. (2011). Contrastive Analysis of Persian and English and error analysis. Tehran: Rahnama Press.

[18] Keshavarz, M. H. (2013). Contrastive analysis and error analysis. Tehran: Rahnama Press.

[19] Mirdeghan, M., Ahmadvand A., and Sadat Hoseini Kargar, N. (2014). Analysis of phonological errors of German- speaking Persian language learners at the elementary level, Research Journal of Persian Language Teaching to Non-Persian Speakers. Third Year, No. 6.

[20] Brumann, C. (1999). Writing for culture: Why a successful concept should not be discarded. Current Anthropology, 40(Suppl), S1-S27.
[21] Chamot, A. U. (1987). The learning strategies of ESL students. In A. Wenden and J. Rubin (Eds.). Learner strategies in language learning (pp. 71-84). London: Prentice- Hall International.

[22] Willing, K. (1988). Learning styles in adult migrant education. Adelaide: National Curriculum Research Council.

[23] Canale, M., Swain, M. (1980). Theoretical Bases of Communicative Approaches to Second Language Teaching and Testing. Applied Linguistics, 1, 1-47.

[24] Kiani, Gh. (2011). The role of language learners' errors in the second language learning process based on cognitive psychology, Journal of Humanities, First Year, No. 5.

[25] Holliday, A. (2008). Standards of English and politics of inclusion. Language Teaching, 41 (1): pp. 119-130.

[26] Trudgill, P. (1984). Accent, dialect and the school. (eds.) Doughty P. and Thornton G. Melbourne: Edward Arnold Publishers Ltd.

[28] Widdowson, 11. G. (1994). The ownership of English. TESOL Quarterly, 28: pp. 377-389.

[27] Verlag, G. N. (2005). The globalization of English and the English language classroom. (eds.) Gnutzmann C. and Intermann F., Tubingen.

[29] Kachru, B. B. and Nelson, C. (1996). World English in S. L. McKay and N. 44 H. Hornbeger (Eds.), Sociolinguistics and language teaching (pp.71-102). Cambridge, England: Cambridge University Press.

[30] Scales, J., Wennerstorm, A., Richard, D. and Hui Wu, S. (2006). Language learners' perceptions of accent. TESOL Quarterly, 40(4): pp. 715-738.

[31] Rajagopalan, K. (2004). The concept of world English and its implications for ELT. ELT. 58(2): pp. 11-118. 